\title{
Resilience from ruin
}

\author{
Five years ago, China was struck by the devastating Wenchuan earthquake. From the destruction \\ comes new understanding.
}

The earthquake that hit the quiet, rural province of Sichuan, China, on 12 May 2008 stands out as one of the most striking natural disasters of recent years. A quake of such high magnitude was unexpected in this midcontinental region, and is one of the deadliest and costliest in the twenty-first century so far. However, the event was recorded in detail and generated large amounts of new data, creating a research bloom that continues today. A web focus published with this issue (http://go.nature.com/TECoT5) explores the marks left by this tragic event, along with the research avenues that have opened up as a result.

The towering heights of the Longmen Shan Mountains hosted the Wenchuan earthquake. Before the quake, faults in the Longmen Shan slipped very slowly and the rocks deformed only gradually, so the risk of a large earthquake was assumed to be low ${ }^{1}$. In hindsight, it seems that the steep mountain peaks themselves - formed by movements along active faults - should have been taken as an indicator that the previously assigned low-to-moderate seismic hazard assessment was wishful thinking ${ }^{2}$.

The quake was catastrophic. Over 80,000 people were killed and millions were left homeless when entire towns tumbled as a result of the shaking and subsequent quake-triggered landslides. The initial government response was commendable. The rapid assembly of military teams and civilian helpers, who headed directly to the affected areas to begin rescue efforts, ensured that thousands of lives were saved. As well as government-led endeavours, a stronger focus on empowering local communities and individuals, with emphasis on educating people on how to prepare for and respond to natural disasters, could reduce the loss of life in future events ${ }^{3}$.

Five years on, much of the rebuilding effort is complete. Entire towns, including new schools and homes, have been built in new locations. That said, the effects of the earthquake are still being felt. The risk of landslides in Sichuan Province remains elevated compared with pre-quake levels, and will remain so for the next ten to twenty years, as large amounts of debris liberated by the quake remain perilously perched on the high slopes of the Longmen Shan.

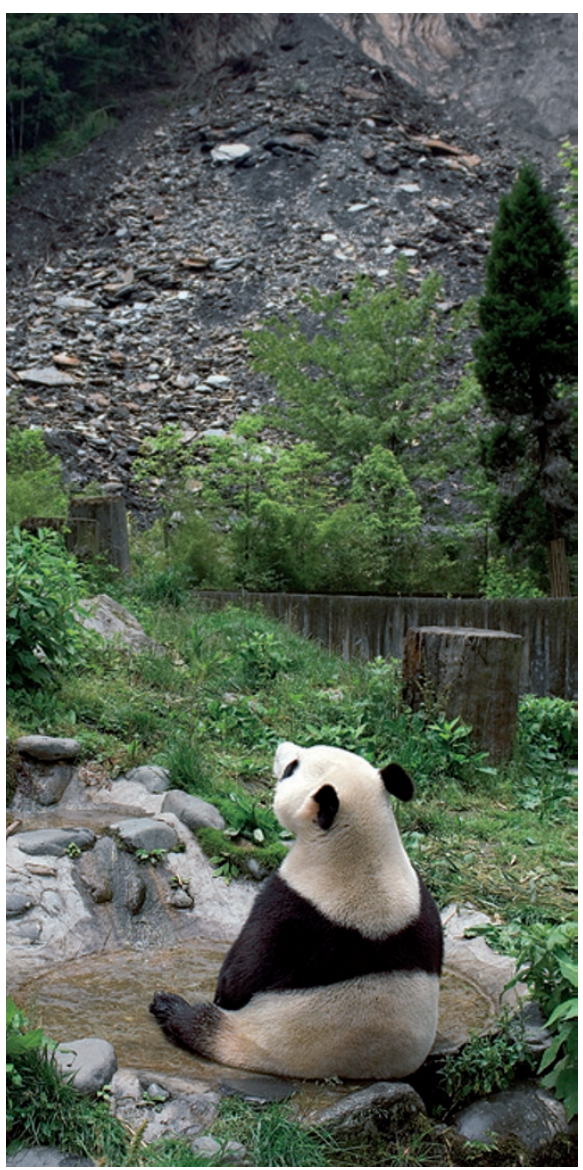

sampling rocks directly from the fault zone ${ }^{6}$. It is now known that rocks in the Longmen Shan are strong and the quake occurred on a remarkably steep fault. The combination of strength and steepness means that the fault is usually locked and barely moves ${ }^{1}$, yet it was able to slip catastrophically in 2008 and seems to do so every few thousand years ${ }^{78}$. Other faults in the region could be capable of producing similarly large earthquakes ${ }^{9}$.

The long-term consequences of earthquakes on the environment are relatively unknown, and the Wenchuan quake has stimulated research in this field, too. The initial outlook was grave. The Sichuan region is a global hotspot for biodiversity and home to much of the world's giant panda population. Quake-triggered landslides stripped the mountainsides bare and buried large swathes of vegetation, including forests and bamboo. Almost one-quarter of panda habitat was destroyed and the remainder was fragmented, isolating the pandas and threatening their ability to feed and breed $^{10,11}$. However, comparison of habitatuse patterns by pandas from before and after the quake reveals no substantial changes so $\mathrm{far}^{12}$. Furthermore, although the primary productivity of vegetation in some quakeaffected areas initially dropped by $22 \%$, it was almost fully recovered just two months later ${ }^{13}$. In terms of the ecological succession, it is still early days and recovery is just beginning. The full impact of the Wenchuan quake will only be understood after many more years of monitoring.

The Wenchuan quake has provided new insights into earthquakes that occur in midcontinental regions, but there is still more to learn. Research efforts must maintain momentum. With increased understanding comes improved resilience.

\footnotetext{
References

1. Zhang, P. Nature Geosci. 6, 323-324 (2013).

2. Kirby, E., Whipple, K. \& Harkins, N. Nature Geosci. 1, 485-487 (2008).

3. Chan, E. Y. Y. Nature Geosci. 6, 327-328 (2013).

4. Huang, R. \& Fan, X. Nature Geosci. 6, 325-326 (2013).

5. Witze, A. Nature 459, 153-157 (2009).

6. Li, H. et al. Tectonophysics 584, 23-42 (2013)

Ran, Y. et al. Tectonophysics 584, 81-90 (2013).

8. Chen, L. et al. Tectonophysics 584, 91-101 (2013)

9. Wang, M. et al. Tectonophysics 584, 102-113 (2013)

10. Stone, R. Science 324, 713-714 (2008).

11. Xu, W. et al. Front. Ecol. Environ. 7, 353-358 (2009).

12. Zheng, W. et al. Biol. Conserv. 145, 241-245 (2012).

13. Liu, Y., Liu, R. G. \& Ge, Q. S. Nat. Hazards 54, 851-862 (2010).
} 